$\begin{array}{cc}\text { ACADEMIA ROMÂNĂ } & \text { Rev. Roum. Chim., } \\ \text { Revo, 65(5), 461-466 } & \text { Rove Roumaine de Chimie } \\ \text { http://web.icf.ro/rrch/ } & \text { DOI: } 10.33224 / \text { rrch.2020.65.5.05 }\end{array}$

\title{
EFFECT OF SOME SOLVENTS ON THE MOLECULAR INTERACTION BETWEEN FILLER/MATRIX: CASE OF PMMA/SiO ${ }_{2}$ NANOCOMPOSITES
}

\author{
Djilali BOULERBA, Abdelhalim ZOUKEL * and Mohamed Benabdallah TAOUTI \\ Laboratory Physico-Chemistry of Materials, PO Box37, 03000, Laghouat, Algeria
}

Received June 9, 2019

\begin{abstract}
Poly (methyl methacrylate) $/ \mathrm{SiO}_{2}$ nanocomposite membranes were made by simple solution mixing procedure, using three different solvents: Acetone, Acetonitrile and Chloroform. FT-IR studies confirm first the formation of H-bond between the matrix (PMMA) and the filler $\left(\mathrm{SiO}_{2}\right)$. Second, the FT-IR peak of bound carbonyl groups was shifted by $9,11 \mathrm{~cm}^{-1}$ and $19 \mathrm{~cm}^{-1}$ in the samples prepared with Acetone, Acetonitrile and Chloroform, respectively. These peak shifts are related to the H-bond interaction strength. The strongest interaction between PMMA and $\mathrm{SiO}_{2}$ was presented in the nanocomposite prepared by Chloroform solvent. In addition, the Studio Software Solution "Material Studio 6.0" was used to calculate the surface interaction energy between the PMMA, $\mathrm{SiO}_{2}$ and solvent. The results of the simulation showed that the Chloroform molecule form the weakest surface interaction energy between both PMMA molecule and Silica particle, which facilitates creating strong interaction between them .The calculated data are in good agreement with the experimental results.
\end{abstract}

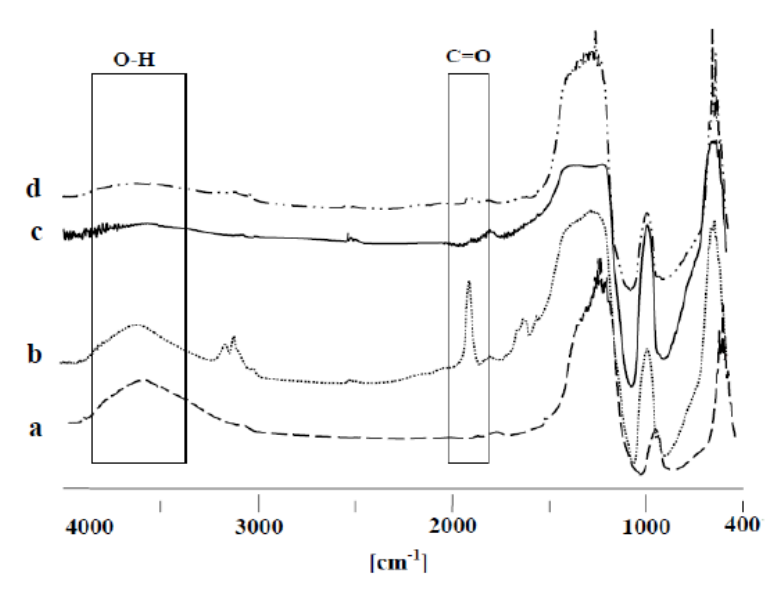

\section{INTRODUCTION}

The interactions between filler and polymer play a very important role in the final properties of nanocomposite materials, such mechanical strength, ${ }^{1-3}$ thermal stability, ${ }^{3,4}$ barrier properties, ${ }^{5,6}$ dimensional stability, ${ }^{7}$ and wear resistance. ${ }^{8}$ The nature and strength of the filler/polymer interaction will condition the filler dispersion and distribution quality into the polymer matrix. In fact, the weak interactions lead to increase the amount of filler agglomerates, while the strong interactions either form mixed aggregates or individually disperse the primary particles. ${ }^{9}$

The FTIR study of the H-bond between $\mathrm{OH}$ $\left(\mathrm{SiO}_{2}\right)$ and $\mathrm{O}=\mathrm{C}$ (PMMA) in $\mathrm{PMMA} / \mathrm{SiO}_{2}$ nanocomposites occupies a position of considerable importance in a number of works. Kulkeratiyut et $a l .{ }^{10}$ have studied the fraction of carbonyl bound in PMMA adsorbed on silica by FTIR transmission. Their results revealed that the translation of the carbonyl-stretching band of bound carbonyls towards lower wave numbers (lower energies) was due to the interaction with the silica silanols surface via the H-bond. Zulfikar et al., ${ }^{11}$ have also confirmed that the peak shift corresponding to the carbonyl group is generally due to the presence of the H-bond. In addition, Krisanangkura et al. ${ }^{12}$ have studied the H-bond between carbonyls and silanols grouping in a series of methacrylate polymers with fumed silica. They showed that the intensity of silanol peak was reduced or eliminated by the H-bonding interactions that take place. Furthermore, A partial shift in vibration frequenc

\footnotetext{
${ }^{*}$ Corresponding author: abdelhalim.zoukel@gmail.com
} 
of carboxyl group $(\mathrm{C}=\mathrm{O})$ was observed, indicating the occurrence of hydrogen bonding between $\mathrm{C}=\mathrm{O}$ and $\mathrm{OH}$ (Z. H. Huang et al. ${ }^{13}$ and Wei Zhang et $\left.a l .{ }^{14}\right)$. It is interesting to note that, Nie et al. ${ }^{15}$ have shown that there is an approximate linear correlation between the $\mathrm{C}=\mathrm{O}$ stretching frequency and the hydrogen-bond strength. They have demonstrate that the stronger the hydrogenbonding interactions, the larger the shift in the $\mathrm{C}=\mathrm{O}$ stretching frequency.

In this article, we report the synthesis and the characterization of $\mathrm{SiO}_{2} / \mathrm{PMMA}$ nanocomposites by simple solution mixing procedure. The aim is to understand how organic solvents influence the molecular interaction between the oxide filler and the polymer matrix. Further, studying the strength of the hydrogen bond created between the filler and the polymer would allow us to have the best experimental conditions leading to the good dispersion and distribution of nanoparticles into polymer matrix.

\section{EXPERIMENTAL RESULTS}

The Infra-red spectra of raw PMMA matrix and raw silica filler are shown in Fig 1. In spectra of raw PMMA samples, absorption peak at $1732 \mathrm{~cm}^{-1}$ is due to the $\mathrm{C}=\mathrm{O}$ carbonyl function groups. The resonances around 2900 to $3000 \mathrm{~cm}^{-1}$ are due to the vibration peaks of $-\mathrm{CH}_{3}$ and $-\mathrm{CH}_{2}$. In spectra of raw Silica samples, bond at $1000-1300 \mathrm{~cm}^{-1}$ corresponds to the peak of Si-O groups. In addition, the broad absorption, centered at $3400 \mathrm{~cm}^{-1}$ is corresponding to the vibration peaks of $\mathrm{Si}-\mathrm{O}-\mathrm{H}$ and $\mathrm{O}-\mathrm{H}$ groups.

As regard the Infra-red spectra of $\mathrm{PMMA} / \mathrm{SiO}_{2}$ nanocomposites (Fig 2), shifts in the vibrational frequencies for the peak of carbonyl $\mathrm{C}=\mathrm{O}$ groups were observed. The absorbance and shift frequencies of the $\mathrm{C}=\mathrm{O}$ bond stretching vibrations in the investigated fragments are presented in Table 1. The greatest shifts in the absorption bands $\left(19 \mathrm{~cm}^{-1}\right)$ are that related to the sample prepared by the Chloroform solvent. Additionally, the disappearance or strong reduction of the $\mathrm{O}-$ $\mathrm{H}$ vibration are generally due to the formation of the $\mathrm{H}$-bond between $\mathrm{PMMA}(\mathrm{C}=\mathrm{O})$ and $\mathrm{SiO}_{2}(\mathrm{O}-\mathrm{H})$.

\section{SIMULATION RESULTS}

The surface interaction energy was calculated for each interface model. The calculated values of $\mathrm{E}_{\text {interaction }}$ for the $\mathrm{SiO}_{2} /$ Solvent and PMMA/Solvent according the equations 1 et 2 are presented in the Table 2. It is obvious from Table 2 that the Chloroform had the weakest binding ability with silica and PMMA, followed by Acetonitrile and Acetone had the strongest. In other words, Chloroform is the optimal solvent for PMMA composites that contain $\mathrm{SiO}_{2}$ particle fillers. The PMMA molecules, Silica particles and the solvents are shown in Fig. 3. The Molecular layer configurations of $\mathrm{SiO}_{2} /$ Solvents and PMMA/ Solvents are also shown in Fig. 4.

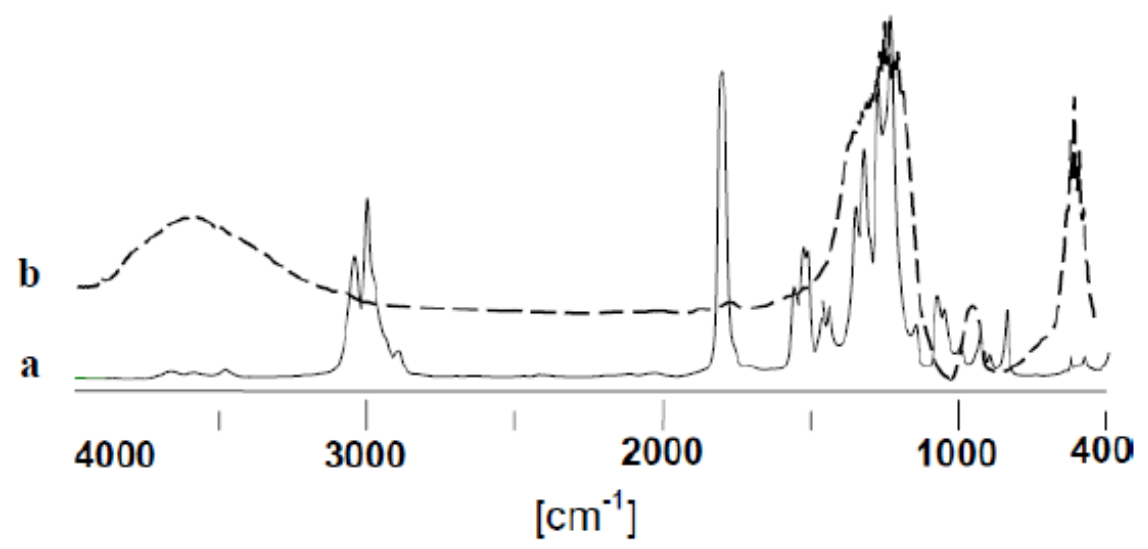

Fig. 1 - FT-IR spectra of raw PMMA (a) and Silica (b).

Table 1

The shift frequencies of the carbonyl group for the samples prepared in three different solvents

\begin{tabular}{ccc}
\hline Solvent & Absorbance ( cm-1) & Shift ( cm-1) \\
\hline Chloroform & 1713 & 19 \\
Acetonitrile & 1721 & 11 \\
Acetone & 1723 & 9 \\
\hline
\end{tabular}




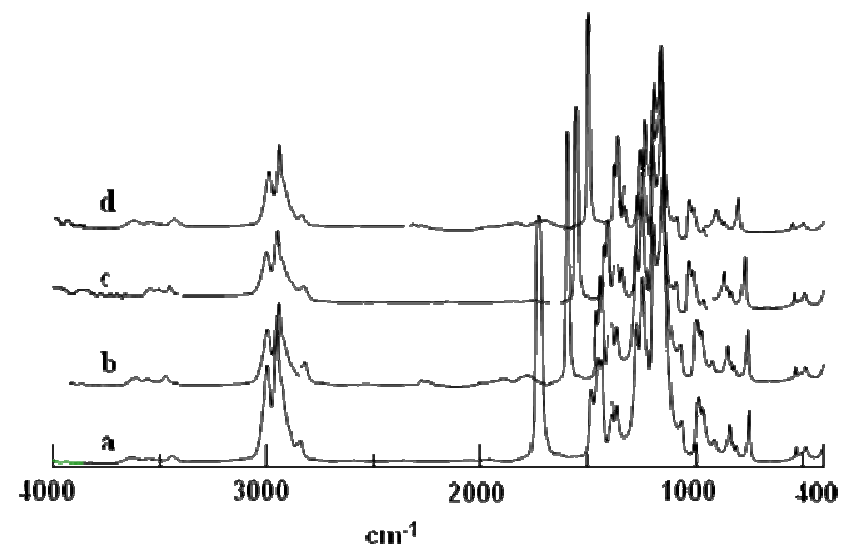

Fig. 2 - FT-IR spectra of raw PMMA (a) and samples prepared in Acetone (b); Acetonitrile (c); Chloroform (d).

Table 2

The surface interaction energy calculated using Materials Studio software between Solvent/Silica and Solvent/PMMA

\begin{tabular}{c|c|c|c}
\hline Molecule & $\mathrm{SiO}_{2}$ - Acetone & $\mathrm{SiO}_{2}$ - Acetonitrile & $\mathrm{SiO}_{2}$ - Chloroform \\
\hline Energy $(\mathrm{kcal} / \mathrm{mol})$ & -15.35 & -19.06 & -24.41 \\
\hline Energy $(\mathrm{kcal} / \mathrm{mol})$ & -21.11 & -23.59 & $\mathbf{- 3 4 . 1 2}$ \\
\hline
\end{tabular}

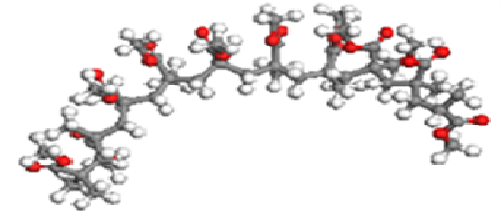

(a)

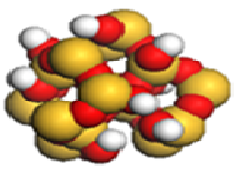

(b)

Fig. 3 - Molecular structure from materials Sudio software: PMMA (a) and Silica (b).

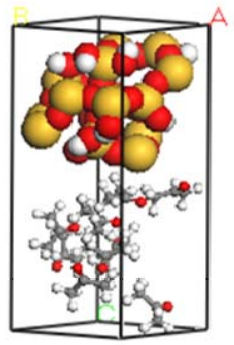

(a)

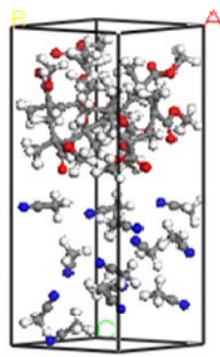

(d)

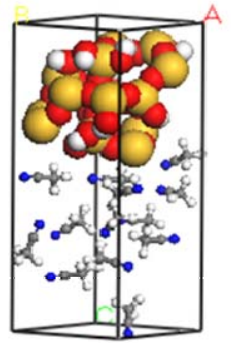

(b)

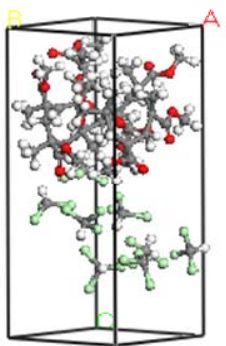

(e)

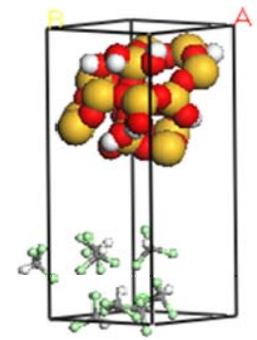

(c)

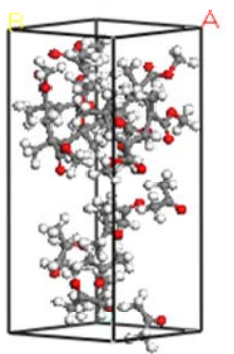

(f)

Fig. 4 - Molecular layer configurations: Silica - Acetone (a); Silica - Acetonitrile (b); Silica - Chloroform (c); PMMA - Acetone(d) ; PMMA - Acetonitrile (e); PMMA - Chloroform (f). 


\section{DISCUSSION}

The objective of this study is to understand how organic solvents influence the molecular interaction between the filler and the matrix in the case of PMMA/ $/ \mathrm{SiO}_{2}$ nanocomposites prepared by simple solution mixing procedure. The strength and the energy of this molecular interaction were investigated experimentally and through calculations. Additionally, polar and apolar solvents with different affinity to the silica surface sites were used for further understand their competition for these sites.

In general, every solvent have different hydrogen bond affinities to the silica surface. Acetone and Acetonitrile act as a hydrogen acceptor whereas Chloroform is a hydrogen donor. ${ }^{16}$ In addition, for apolar solvents such as Chloroform, the absence of polar (side) groups implies a weak interaction with polar polymer repeat unit (PMMA) compared to the polar solvents (as Acetone and Acetonitrile). These mechanisms favor the interaction between the PMMA molecules and the $\mathrm{SiO}_{2}$ particles for samples prepared by Chloroform solvent. In comparison, the higher adsorption of the Acetone molecules on the surface of silica particle allows the formation of a strong H-bond between the Acetone carbonyl group and the Silica hydroxide group. Furthermore, the strong polar interaction between the Acetone carbonyl group and the polymer repeat unit allow also the formation of a strong H-bond. Consequently, for samples prepared by acetone solvent, the molecular interaction between the PMMA molecules and the $\mathrm{SiO}_{2}$ particles will be weakened. Finally, the Acetonitrile molecules have less adsorption on silica surface than the Acetone molecules. This is due to the lack of possibility of H-bonding. As a result, the interactions between PMMA and Silica, for samples prepared by Acetonitrile solvent, became more effective compared to the Acetone system.

These results can be explained, first, by the shift of $\mathrm{C}=\mathrm{O}$ wave numbers characteristic band and, second, by the strength of the surface interaction energy calculated with DM simulations. The $\mathrm{C}=\mathrm{O}$ peak shift was significantly more valuable for samples prepared using Chloroform solvent compared with those prepared using Acetone and Acetonitrile solvents. In fact, the phase separated system was confirmed by the lower shift of $\mathrm{C}=\mathrm{O}$ wave numbers characteristic band and the weaker interaction energy.

The extraction technique, which is mainly used, is the simplest way to confirm more the experimental results obtained above. This technique involves immersing the nanocomposites sample in a solvent three times to remove all extractable polymers. Then, the dried residues obtained will be characterized by the FT-IR spectroscopy to follow the traceability of the carbonyl groups in our samples. Although, previous studies have used this technique, such Wang et al., ${ }^{17}$ to prove that the disappearance of $\mathrm{C}=\mathrm{O}$ stretching vibration after extraction means that there is no PMMA molecules absorbed physically on $\mathrm{SiO}_{2}$ nanoparticles.

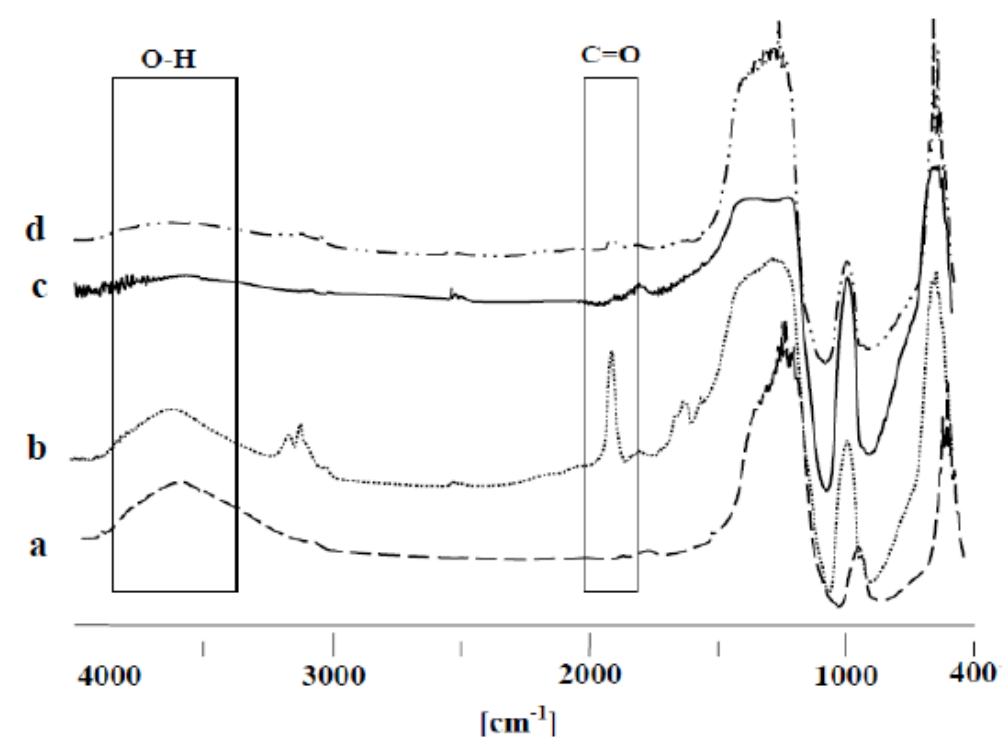

Fig. 5 - FT-IR spectra of raw Silica (a); with Chloroform (b), with Acetone (c) and with Acetonitrile (d) Soxhlet extraction solution. 
In Fig. 5, we display the infrared spectra of the eluate, while three times of extracting, and pure silica. It can be seen that the peak at $1713 \mathrm{~cm}^{-1}$ in Chloroform spectra is assigned to $\mathrm{C}=\mathrm{O}$ stretching vibration of PMMA, which was disappeared in Acetone and Acetonitrile. This indicates that the PMMA molecules were absorbed physically on $\mathrm{SiO}_{2}$ nanoparticles for samples prepared with Chloroform. The results of extraction confirm that the PMMA/Silica interactions in the samples prepared with Chloroform are stronger than samples prepared with Acetone and Acetonitrile.

\section{EXPERIMENTAL PROCEDURE}

\section{Materials}

In our study, commercially available PMMA was used as a matrix for preparing samples (grade: $\operatorname{Acryrex}^{\circledR}$ CM205, $\mathrm{Mw} \approx 90,400 \mathrm{~g} / \mathrm{mol}$, manufactured by the Chi Mei Corporation). The fillers were fumed colloidal silica (Grade: Cab-O-Sil ${ }^{\circledR}$ M-5P; manufactured by the Cabot Corporation). The fumed silica nanoparticles are non-porous, have a spherical shape of 7-15 nm in diameter with a specific surface area of $200 \pm 25 \mathrm{~m}^{2} / \mathrm{g}$. Solvent as Acetone, Acetonitrile and Chloroform were used to prepare $\mathrm{PMMA} / \mathrm{SiO}_{2}$ films.

\section{Preparation of nanocomposites}

As mentioned above, the nanocomposites films of PMMA/SiO ${ }_{2}$ were synthesized by simple solution mixing procedure $^{18}$ (Fig. 6). The PMMA $(0.57 \mathrm{~g})$ and the silica nanoparticles $(0.03 \mathrm{~g})$ were dissolved simultaneously in the solvent $(40 \mathrm{~mL})$. In order to obtain a homogeneous solution, the mixture was followed by magnetic stirring for 2 hours at a temperature of $40{ }^{\circ} \mathrm{C}$. Afterwards, to ensure the evaporation of the solvent, the mixture (in viscous solution form) was dried at $40{ }^{\circ} \mathrm{C}$ for 4 hours.

\section{Characterization}

Fourier Transform Infrared (FT-IR) transmission spectra were recorded on a BIO-RAD FTS-165 spectrometer. The results were collected in wave numbers between 4000 and 450, $1 \mathrm{~cm}^{-1}$ resolution, 128 scans, and $40 \mathrm{kHz}$ scanning velocity using an MCT detector. Samples were made directly in the transmission mode from dried casts deposited on $\mathrm{KBr}$ pellet.

\section{SIMULATION PROCEDURE}

Molecular dynamics simulations were performed using Material Studio package (v. 6.0, supplied by Accelrys Inc., San Diego, CA, USA). Compass force field for inter and intra-atomic interaction was used together with Forcite and Amorphous Cell Module. The simulation procedure consists of the following five major steps.

The crystal structure of silica nanoparticles ( $\alpha$-quartz) was obtained from the Cambridge Structural Database with lattice parameters as follows: space group P3321; $\mathrm{a}=\mathrm{b}=4.91 \mathrm{~A}^{\circ}$ and $\mathrm{c}=5.402 \mathrm{~A}^{\circ} ; \alpha=\beta=90^{\circ}$ and $\gamma=120^{\circ}$. Silica nanoparticles have a spherical form and similar diameters $\left(10 \mathrm{~A}^{\circ}\right)$. Hydrogen atoms and hydroxyl groups were added to unsaturated $\mathrm{O}$ and $\mathrm{Si}$ atoms, respectively, to ovoid unsaturated boundary effect of the $\mathrm{SiO}_{2}$ particle surface.

Amorphous Cell module was used in order to build accurate models of PMMA and solvents molecules and to predict their key properties. The molecules of PMMA and solvents were constructed "using discover module" in threedimensional cubic unit cells with periodic boundary conditions.

The PMMA/Solvent, Silica/Solvent and the PMMA/Silica surface systems were then constructed by Build Layer module. A geometrical energy minimization scans were performed using Forcite module to achieve the stability of the system. The subsequent simulation was based on those layer structures.

The Compass force field has been selected for modeling interatomic interactions and to calculate the surface properties of the layer material. For the non-bonding terms, Van-Der-Waals interaction and Coulombic interaction energies were included for both force fields, but no hydrogen bonding energy terms were explicitly included in the Compass force field.

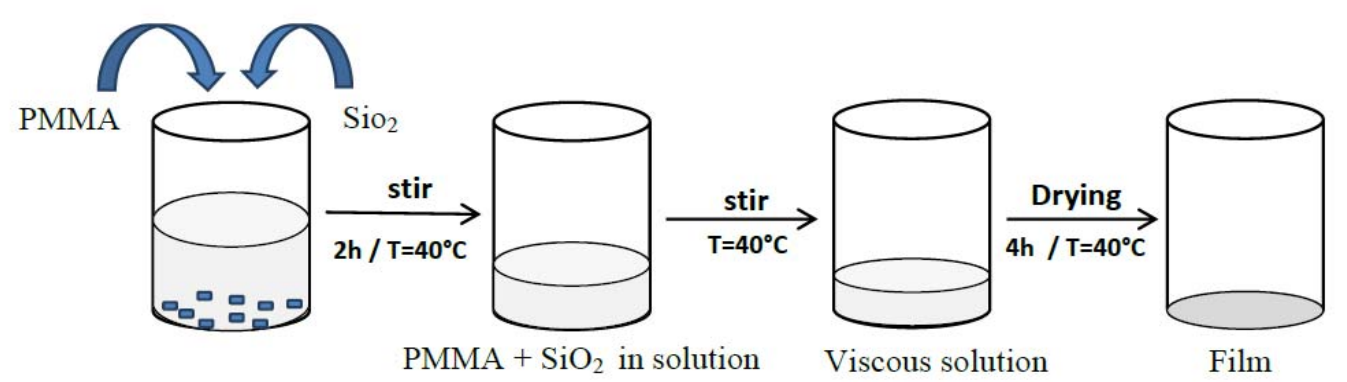

Fig. 6 - Experimental set-up of samples preparation. 
Molecular dynamics simulations runs were equilibrated for $500 \mathrm{ps}$ at $298 \mathrm{~K}$ with time step of $1 \mathrm{fs}$ in the NVT ensemble (constant number of particles, $\mathrm{N}$, volume, $\mathrm{V}$, and temperature, $\mathrm{T}$ ). This protocol was followed for all simulated structures.

The interaction energy among molecules $(E$ interaction) was calculated according to the following equation:

$$
\begin{gathered}
E_{\text {interaction }}=E_{\text {total }}-\left(E_{\mathrm{SiO} 2}+E_{\text {solvent }}\right) \\
E_{\text {interaction }}=E_{\text {total }}-\left(E_{\mathrm{PMMA}}+E_{\text {solvent }}\right)
\end{gathered}
$$

\section{CONCLUSIONS}

The effect of the solvent on the interaction between the matrix and the filler was studied using FT-IR spectroscopy and the molecular dynamics simulations. For this purpose, $\mathrm{PMMA} / \mathrm{SiO}_{2}$ nanocomposites prepared with three different solvents (Acetone, Acétonitrile and Chloroform) were investigated. Based on the infra-red spectra, the experimental results showed that the strongest $\mathrm{H}$-bond interaction between the matrix (PMMA) and the filler (Silica) was found on the samples prepared with Chloroform. In addition, the simulation results revealed that Chloroform molecule (compared to acetone and Acetonitrile molecules) form the weakest surface interaction energy between both PMMA and Silica. These results indicate that the strong interaction between
PMMA and Silica could be obtained throught use of the Chloroform as solvent.

\section{REFERENCES}

1. H. Wang, C. Zeng, M. Elkovitch, L. J. Lee and K. W. Koelling, Polym. Eng. Sci., 2004, 41, 2036-2046.

2. U. Schubert, Chem. Mater., 2001, 13, 3487-3494.

3. E. P Giannelis, Adv. Mater., 1996, 8, 29-35.

4. J. W. Gilman, Appl. Clay Sci., 1999, 15, 31-49.

5. S. Pavlidou andC. D. Papaspyrides, Prog. Polym. Sci., 2008, 33, 1119-1198.

6. A. Kalendova, D. Merinska, J. F. Gerard and M. Slouf, Polym. Compos., 2013, 34, 1418-1424.

7. C. Zeng, X. Han, L. J. Lee, K. W. Koelling and D. L. Tomasko, Adv. Mater., 2003, 15, 1743-1747.

8. M. Z. Rong, K. Friedrich, H. Liu, H. Zeng and B. Wetzel, Ind. Lubr. Tribol., 2012, 53, 72-77.

9. J. Shao, Y. Yuan, R. Zhang, M. Wu and D. Qi, Acta Polym. Sinica, 2011, 7, 745-751.

10. S. Kulkeratiyut, S. Kulkeratiyut and F. D. Blum, $J$. Polym. Sci., Part B: Polym. Phys., 2006, 44, 2071-2078.

11. M. A. Zulfikar, A. W. Mohammad, A. Kadhum andN. Hila, J. Appl. Polym. Sci., 2006, 99, 3163-3171.

12. P. Krisanangkura, A. M. Packard, J. Burgher and F. D. Blum, J. Polym. Sci., Part B: Polym. Phys., 2010, 48, 1911-1918.

13. Z. H. Huang and K. Y. Qiu, Polymer, 1997, 38, 521-526.

14. W. Zhang, A. A. Dehghani-Sanij and R. S. Blackburn, Prog. Natur. Sci., 2008, 18, 801-805.

15. B. Nie, J. Stutzman and A. Xie, Biophys J., 2005, 88, 2833-2847.

16. N. N. Casillas-Ituarte and H. C. Allen, Chemi. Phys. Lett., 2009, 483, 84-89.

17. Q. Wang, Y. Luo, C. Feng, Z. Yi, Q. Qiu, L. X. Kong and Z. Peng, J. Nanomater., 2012, 9-19.

18. A. Benmiloud, D. Boulerba and A. Zoukel, J. Sci. Eng. Sci., 2020, 9, 12-18. 